\title{
Deciphering the complexity of the $4 q$ and $10 q$ subtelomeres by molecular combing in healthy individuals and patients with facioscapulohumeral dystrophy
}

\author{
Karine Nguyen, ${ }^{1,2}$ Natacha Broucqsault, ${ }^{2}$ Charlene Chaix, ${ }^{1}$ Stephane Roche, ${ }^{2}$ \\ Jérôme D Robin, ${ }^{2}$ Catherine Vovan, ${ }^{1}$ Laurene Gerard, ${ }^{1}$ André Mégarbané, ${ }^{3}$ \\ Jon Andoni Urtizberea, ${ }^{4}$ Remi Bellance, ${ }^{5}$ Christine Barnérias, ${ }_{1}^{6,7}$ Albert David, ${ }^{8}$ \\ Bruno Eymard, ${ }^{9}$ Melanie Fradin, ${ }^{10}$ Véronique Manel, ${ }_{1}^{11}$ Sabrina Sacconi, ${ }^{12,13}$ \\ Vincent Tiffreau, ${ }^{14}$ Fabien Zagnoli, ${ }^{15}$ Jean-Marie Cuisset, ${ }^{16}$ \\ Emmanuelle Salort-Campana, ${ }^{2,17}$ Shahram Attarian, ${ }^{2,17}$ Rafaëlle Bernard, ${ }^{1,2}$ \\ Nicolas Lévy, ${ }^{1,2}$ Frederique Magdinier ${ }^{\odot 2}$
}

\begin{abstract}
- Additional material is published online only. To view please visit the journal online (http://dx.doi.org/10.1136/ jmedgenet-2018-105949).
\end{abstract}

For numbered affiliations see end of article.

\section{Correspondence to} Dr Frederique Magdinier, Marseille Medical Genetics U1251, Aix-Marseille Universite Faculte de Medecine, Marseille, France;

frederique.magdinier@univamu.fr

$\mathrm{KN}$ and NB contributed equally.

Received 17 December 2018 Revised 28 February 2019 Accepted 24 March 2019 Published Online First 22 April 2019

\section{Check for updates}

(C) Author(s) (or their employer(s)) 2019. No commercial re-use. See rights and permissions. Published by BMJ.

To cite: Nguyen $\mathrm{K}$,

Broucqsault N, Chaix C, et al. $J$ Med Genet

2019:56:590-601.

\section{ABSTRACT}

Background Subtelomeres are variable regions between telomeres and chromosomal-specific regions. One of the most studied pathologies linked to subtelomeric imbalance is facioscapulohumeral dystrophy (FSHD). In most cases, this disease involves shortening of an array of D4Z4 macrosatellite elements at the $4 q 35$ locus. The disease also segregates with a specific A-type haplotype containing a degenerated polyadenylation signal distal to the last repeat followed by a repetitive array of $\beta$-satellite elements. This classification applies to most patients with FSHD. A subset of patients called FSHD2 escapes this definition and carries a mutation in the SMCHD1 gene. We also recently described patients carrying a complex rearrangement consisting of a cis-duplication of the distal 4q35 locus identified by molecular combing.

Methods Using this high-resolution technology, we further investigated the organisation of the $4 q 35$ region linked to the disease and the 10q26 locus presenting with $98 \%$ of homology in controls and patients.

Results Our analyses reveal a broad variability in size of the different elements composing these loci highlighting the complexity of these subtelomeres and the difficulty for genomic assembly. Out of the 1029 DNA samples analysed in our centre in the last 7 years, we also identified 54 cases clinically diagnosed with FSHD carrying complex genotypes. This includes mosaic patients, patients with deletions of the proximal $4 q$ region and 23 cases with an atypical chromosome 10 pattern, infrequently found in the control population and never reported before.

Conclusion Overall, this work underlines the complexity of these loci challenging the diagnosis and genetic counselling for this disease.

\section{INTRODUCTION}

Subtelomeres are highly variable DNA sequences lying at the interface between telomeres and chromosome-specific regions. The rate of recombination at subtelomeres is higher than in the rest of the genome and subtelomeric variation contributes to genome variability and to a wide range of diseases from acquired and common ones to rare genetically inherited syndromes. ${ }^{1-3}$ In addition, these telomere-adjacent DNA sequences are crucial for telomere regulation and integrity. ${ }^{4}$ Subtelomeres contain both coding and non-coding transcripts and promoters for the non-coding telomeric repeat-containing RNA transcribed from the subtelomere into the (TTAGGG)n telomeric tract. ${ }^{5}$ Composition of subtelomeric regions in terms of sequence (haplotype) and DNA copy number contribute to the higher-order chromatin organisation of these chromosomal regions, abutting telomeres, and regulation of genes in close proximity by telomere position effect ${ }^{6-9}$ or at a long distance, in a discontinuous manner through formation of long-distance loops. ${ }^{10-13}$

Facioscapulohumeral dystrophy (FSHD) is one of the most puzzling genetic diseases linked to subtelomeric imbalance. In the majority of patients (FSHD1, 95\%), this autosomal dominant neuromuscular disorder ranked as the most common neuromuscular hereditary disorder with a prevalence of 1:8000-1:20 000 is not linked to a mutation affecting the coding sequence of a protein involved in muscle function but to a deletion of an integral number of repetitive D4Z4 macrosatellites at the $4 \mathrm{q} 35$ chromosome end. ${ }^{14} 15$ Clinically, symptoms usually arise between the age of $20-40$ years with a typical asymmetrical weakness of facial, scapular girdle, upper limb and lower extremities muscles. $^{16}$

The locus linked to the pathology is located in the subtelomeric region of the $4 \mathrm{q}$ arm. ${ }^{17}{ }^{18}$ In the control population, the number of repeated units of this $3.3 \mathrm{~kb}$ GC-rich element is between 11 and 150 copies (eg, $>35 \mathrm{~kb}$ and up to an estimated size of $495 \mathrm{~kb}$ ) whereas in patients with FSHD1, one of the D4Z4 arrays carried by the $4 \mathrm{q} 35$ allele is 
contracted and contains between 1 and 10 units with a threshold size $<35 \mathrm{~kb}^{19}$ Distal to D4Z4, two main sequences have been described, termed $\mathrm{qA}$ and $\mathrm{qB}$ haplotypes. ${ }^{20}$ The $4 \mathrm{qA}$ sequence is characterised by the presence of a 260 bp sequence called pLAM containing a degenerated polyadenylation signal for the DUX4 retrogene encoded by D4Z4. The pLAM is followed by an estimated array of $6.2 \mathrm{~kb}$ containing tandem copies of $68 \mathrm{bp} ß$-satellites. $^{20-22}$ The $4 \mathrm{qB}$ sequence is $92 \%$ homologous to $4 \mathrm{qA}$ but contains a LINE sequence. The $10 \mathrm{q} 26$ region is approximately $98 \%$ identical to the $4 \mathrm{qA}$ end in the $40 \mathrm{~kb}$ proximal to D4Z4 and at least $10 \mathrm{~kb}$ distal to the repeat. ${ }^{212324}$ On this chromosome, the number of D4Z4 is variable. In addition, SSLP analyses of the 4qter region revealed the existence of microsatellites of different sizes upstream of D4Z4 with at least three different haplotypes for the $4 \mathrm{qA}$ allele and six haplotypes for $4 \mathrm{qB} .{ }^{24}$ The current model explaining the pathogenesis of the disease postulates that in FSHD1, chromatin relaxation linked to shortening of the D4Z4 array or to mutation in SMCHD1 in FSHD2 causes overexpression of the DUX4 transcript encoded by D4Z4. DUX4 is transcribed from the last D4Z4 repeat and through the distal pLAM sequence containing a degenerated polyadenylation site required for stabilisation of the transcript and production of the DUX4 protein.

In most routine laboratories, FSHD diagnosis is based on a Southern blot (SB) technique after digestion of genomic DNA with the EcoRI enzyme and hybridisation of the p13E-11 probe (D4F104S1) that maps to the proximal region adjacent to the first D4Z4 repeat. However, in approximately 20\% of cases, this technique fails to provide a clear conclusion regarding the number of repeated units and haplotype and remains inconclusive due, for instance, to somatic mosaicism, 4q-10q translocations, p13E-11 deletion or existence of other non-canonical variants. $^{2526}$ To bypass these limitations and provide a method allowing a direct assessment of the size of the D4Z4 array on both the $4 \mathrm{q}$ and $10 \mathrm{q}$ chromosomes together with the type of haplotype, we have developed a molecular combing (MC)-based strategy. ${ }^{27}$ This technology originally developed to map genes for positional cloning and widely used to study DNA replication shares most of the advantages of FISH, with a 100-fold improved resolution. ${ }^{28}$ In addition, MC allows the direct visualisation and cartography of numerous individual DNA molecules at a resolution of $1 \mathrm{~kb}^{28} 29$ and a high reproducibility due to the constant stretching of DNA molecules on glass slides. For FSHD, its main advantage is to allow the direct visualisation of the relevant $4 \mathrm{q} 35$ and $10 \mathrm{q} 26 \operatorname{loci}^{27}$ and appeared as a powerful tool for molecular diagnosis of FSHD and resolution of complex cases. ${ }^{25} 27$

Here, we exploited data gathered from hundreds of individuals analysed by DNA combing to determine the genetic organisation of the 4q35 and 10q26 loci. By analysing more than 400 $4 \mathrm{q}$ and $10 \mathrm{q}$ alleles, we determined the mean size of D4Z4 arrays in the different contexts, the size and distribution of the qA-specific and $\mathrm{qB}$-specific sequences and organisation of the region upstream of the D4Z4 repeats. Our results reveal an important variability between samples and the complexity in realising a complete assembly of these subtelomeric regions. Subsequently, we report analyses of individuals clinically affected with FSHD and displaying atypical genotypes, such as $4 \mathrm{q}$ mosaicism or p13E-11 probe deletion. We also report 23 cases clinically diagnosed with FSHD and carrying an atypical chromosome 10 pattern, infrequently found in the control population and never reported before.

\section{Statement of objectives}

Exploit the resolution provided by MC and bar coding of the $4 q 35$ and 10q26 subtelomeric loci to uncover the complexity of these regions in individuals affected with FSHD and in the general population.

Materials and methods

Materials and Methods are detailed in the online supplementary information section.

\section{RESULTS AND DISCUSSION Analysis strategy}

Since the validation of $\mathrm{MC}$ for the molecular diagnosis of FSHD,${ }^{27}$ we have processed 1029 blood samples from index cases or relatives (figure 1A-D). A number of cases were referred to our Medical Genetics Department for FSHD molecular diagnosis and exclusion diagnosis or familial segregation studies. After initial steps of validation of the technique, ${ }^{27}$ we have used the combing methodology to test in priority patients for whom ambiguous results were obtained by SB (either positive or negative). The major advantage of $\mathrm{MC}$ is the direct visualisation of the haplotypes allowing a straightforward interpretation, especially in complex situations. For SB, we considered unequivocal blotting results where four alleles (two signals for $4 \mathrm{q}$ and $10 \mathrm{q}$ alleles) were clearly visible and additional alleles were absent. Atypical profiles systematically led to the processing of the blood sample by MC. We considered as atypical profiles the absence of one of the four alleles, suggestive of a proximal deletion, the presence of an additional band suggesting the presence of an additional allele or mosaicism and samples for which we observed a discrepancy between the molecular diagnosis results and those expected to carry the genomic anomaly according to the clinical data but showing absence of the short D4Z4 repeat. We also included patients carrying a contracted $4 \mathrm{q}$ allele with a size close to the pathological threshold (greater or equal to eight units) in order to verify the association of this shortened D4Z4 array with the distal qA variant. In addition, since the development of the test, a proportion of patients were tested directly by MC. Those correspond, for example, to relatives of an index case previously explored with an unequivocal result when segregation of the pathological allele was needed. A number of cases were also diagnosed directly by MC.

The diagnosis of FSHD1 was confirmed in $32.26 \%$ of the samples tested for whom only one contracted $4 \mathrm{qA}$ allele was unambiguously present (332 cases out of the 1029 cases analysed, table 1). Presence of a short D4Z4 allele or FSHD1 was discarded for $61 \%$ of the individuals tested. In this group, the four alleles (4q and $10 q$ ) were unambiguously distinguished, with no contracted $4 \mathrm{qA}$ allele or other variant. This second group includes individuals clinically affected with FSHD classified as FSHD2 (figure 1F). In this subgroup of 627 samples, we identified 15 cases carrying a mutation in SMCHD1 (1.45\% of the total cohort of 1029 samples and 3.5\% of affected cases). Cases referred to our centre for exclusion diagnosis are individuals presenting with an undiagnosed neuromuscular disorder. Other cases are individuals explored in case of familial segregation analysis or prenatal testing.

Among the 1029 patients reported here, we previously described complex rearrangements consisting of a cis-duplication of a long D4Z4 array ( $>35 \mathrm{~kb}$ in most cases) and a distal short D4Z4 array $(<35 \mathrm{~kb})$ in 14 patients affected with FSHD. ${ }^{25}$ Nine additional patients have been diagnosed with the same type of cis-duplication. This group of patients represents $2.14 \%$ of 
A
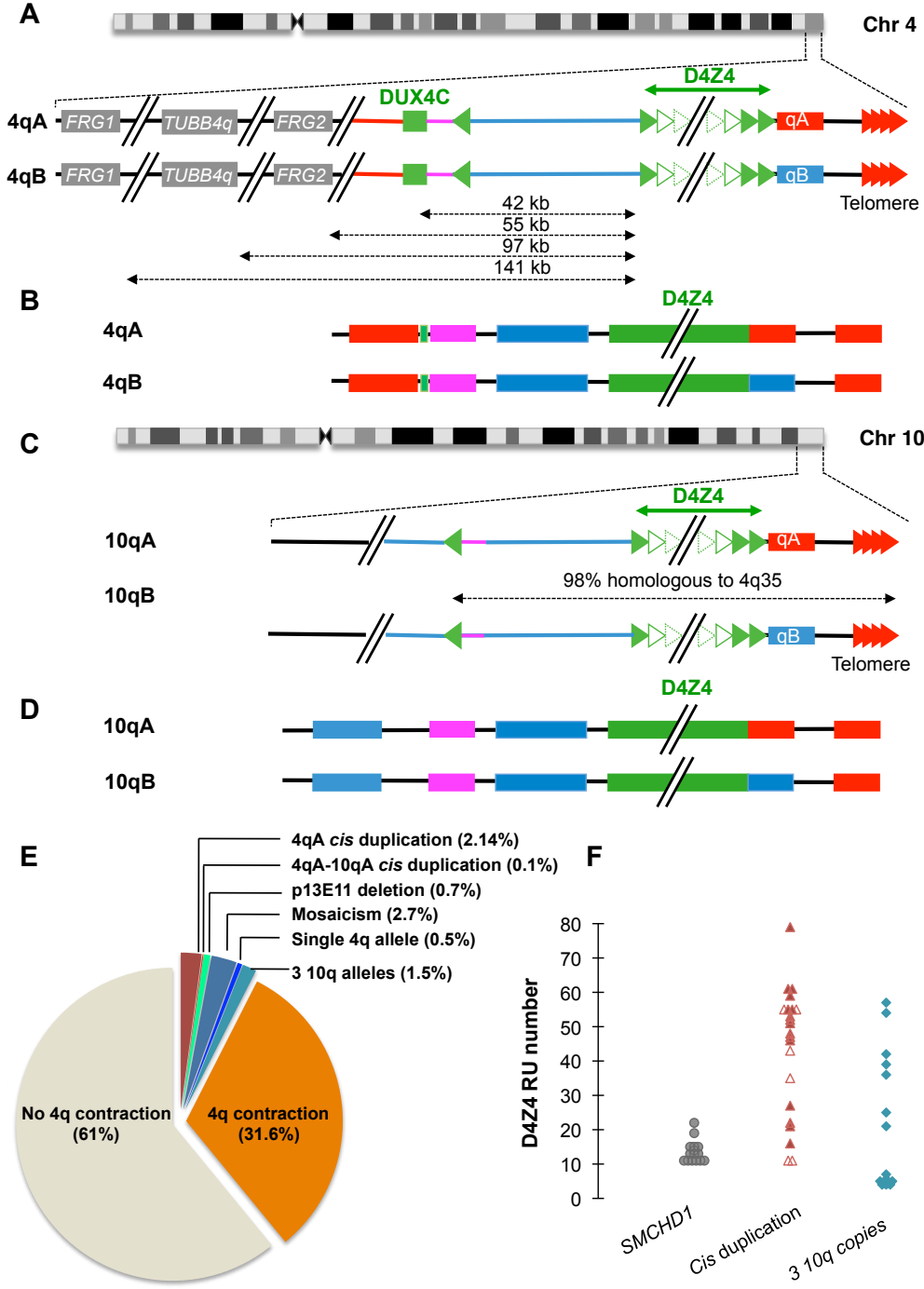

Figure 1 Schematic representation of the $4 q 35$ and $10 q 36$ loci and respective bar codes. (A) Schematic representation of the $4 q 35$ subtelomeric locus. from left to right, the $F R G 1, T U B B 4 Q$ and $F R G 2$ genes are indicated. Sequences starting with an inverted D4Z4 repeat (green arrow), are specific to the $4 q 35$ locus (red lines) while regions located between the D4Z4 array and the inverted D4Z4 repeat are also present on chromosome 10 (10q26 locus). The D4Z4 array is depicted by green triangles. The $4 q A$ and $4 q B$ haplotypes correspond to different genomic elements distal to D4Z4. The 4qA (red rectangle) is characterised by the presence of a sequence named pLAM immediately distal to the last D4Z4 repeat and followed by an array of repeated $\beta$-satellite elements associated with a $4 q A$ haplotype upstream of the telomere (red arrows). The $4 q B$ allele (depicted as a blue rectangle) differs from the $4 q A$ by the absence of $\beta$-satellite elements upstream of the telomere (red arrows). (B) Illustration of the V3 pink bar code used to distinguish the two $4 q$ alleles ( $q A / B$ ) based on a combination of four different colours and different DNA probes encompassing the distal regions up to the telomeric sequence as previously described. ${ }^{27}$ This four-colour bar code comprises one probe detected in blue and one in pink, which hybridise the proximal region common to chromosomes 4 and 10, one $6 \mathrm{~kb}$ probe detected in red, which hybridises the (TTAGGG)n telomeric ends and a red probe that hybridises the qA-specific $\beta$-satellite region. The qB-specific probe, immediately adjacent to D4Z4, is detected in blue. The proximal $4 q$-specific region is detected by a combination of red and pink probes. (C) Schematic representation of the 10q36 locus. This locus shares $98 \%$ of homology with the $4 \mathrm{q} 35$ locus (dashed arrow) starting from a truncated inverted D4Z4 repeat (green arrow) and the same organisation in its distal part, with a variable-length D4Z4 array A-type and B-type haplotype abutting the telomere. (D) Illustration of the V3 pink bar code used to distinguish the two 10q alleles (qA/B) based on a combination of four different colours and different DNA probes encompassing the distal regions up to the telomeric sequence. The bar codes for the $4 q-10 q$ homologous regions are identical. The proximal $10 q$-specific region is identified by hybridisation with a blue probe. (E) Out of the 1029 patients analysed, $92.5 \%$ showed a normal profile with four distinct alleles and absence $(61 \%, 627$ cases) or presence $(31.6 \%, 318$ cases) of D4Z4 array contraction on a 4qA allele. We identified $7.7 \%$ of cases with an atypical profile with $2.7 \%$ of patients with a mosaic D4Z4 array contraction, $2.14 \%$ of patients with a $4 q A$ cis-duplication, $0.7 \%$ of cases with a deletion of the p13E-11 probe and $1.5 \%$ with either a surnumerary $10 q$ allele, a complex rearrangement of the $10 q$ chromosome or both a $4 q$ and $10 q$ rearrangement. (F) We plotted the number of residual D4Z4 repeats of the shortest 4q35 allele in patients with FSHD2 carrying a mutation in SMCHD1 (grey circles), in patients carrying a cis-duplication of the $4 \mathrm{q} 35$ region from patients described $\mathrm{in}^{25}$ and newly diagnosed patients (nine cases) (red triangles, patients with white filling are carrier of a SMCHD1 mutation) and patients in which we found an additional copy of chromosome 10 (blue diamonds, table 1). 
Table 1 Summary of molecular combing (MC) data for analysis of 1029 cases comprising 426 individuals diagnosed with FSHD.

\begin{tabular}{|c|c|c|c|}
\hline & $\begin{array}{l}\text { Number } \\
\text { of } \\
\text { samples }\end{array}$ & $\begin{array}{l}\text { Per cent of } \\
\text { total cases } \\
\text { analysed by } \\
\text { MC } \\
(\mathrm{n}=1029)\end{array}$ & $\begin{array}{l}\text { Per cent of } \\
\text { patients clinically } \\
\text { affected with FSHD } \\
(n=426)\end{array}$ \\
\hline Total number of cases & 1029 & $100 \%$ & 41.4 \\
\hline Absence of contracted $4 q A$ allele & 612 & $59.5 \%$ & 59.5 \\
\hline $\begin{array}{l}\text { Absence of contracted } 4 q \text { allele } \\
\text { and presence of SMCHD1 } \\
\text { mutation }\end{array}$ & 15 & $1.45 \%$ & 3.52 \\
\hline Contracted $4 \mathrm{qA}$ allele & 332 & $32.26 \%$ & 78 \\
\hline 4qA cis-duplication & 22 & $5.4 \%$ & 5.16 \\
\hline 4qA-10qA cis-duplication & 1 & $0.1 \%$ & 0.23 \\
\hline $4 q A$ mosaicism & 27 & $2.66 \%$ & 6.34 \\
\hline p13E-11 deletion & 7 & $0.7 \%$ & 1.64 \\
\hline Detection of a single $4 q$ allele & 5 & $0.5 \%$ & 1.2 \\
\hline Presence of $310 q$ alleles & 16 & $1.5 \%$ & 3.75 \\
\hline
\end{tabular}

FSHD, facioscapulohumeral dystrophy.

the 1029 cases analysed and 5.38\% of all patients described in this cohort. Besides, we found a number of additional atypical genotypes including mosaic cases $(2.6 \%$ of the total number of cases; $6.34 \%$ of patients with FSHD), deletion of the p13E-11 probe $(0.7 \%$ of the total number of cases; $1.64 \%$ of patients with FSHD). We also found a significant number of patients harbouring the presence of an additional $10 \mathrm{q}$ allele $(1.5 \%$ of the total number of cases; $3.75 \%$ of patients with FSHD) (table 1).

\section{Determination of the D4Z4 array size by MC at the $4 q$ and $10 \mathrm{q}$ subtelomeres}

Estimation of the number of D4Z4 repeats at the $4 \mathrm{q}$ and $10 \mathrm{q}$ loci have been mainly based on SB analyses, with a low resolution especially for large DNA fragments. MC facilitates high-resolution analysis of a given genomic region thanks to the combination of specific DNA probes and the constant stretching of DNA molecules on glass slides. ${ }^{28}{ }^{29}$ Moreover, standardisation of the processing and analysis facilitates in-depth characterisation of complex genomic regions. We thus took advantage of this methodology to determine the size of the long and short D4Z4 array on $4 \mathrm{qA}$ and $4 \mathrm{qB}$ chromosomes (figure $2 \mathrm{~A}$ ). For A-type haplotypes, the mean size of long D4Z4 arrays (>35 kb) is $108.9 \mathrm{~kb}$ (33 units) and ranges between $35 \mathrm{~kb}$ and $338 \mathrm{~kb}$ (11 to 102 units) (online supplementary table 1). In patients with FSHD1, the mean size of the short D4Z4 allele is $18 \mathrm{~kb}$ corresponding to five units.

We also analysed a large number of $4 \mathrm{qB}$ alleles with size ranging between 3 and 106 repeated D4Z4 units (11.6-350 $\mathrm{kb})$. Interestingly, we only observed a low number of short $4 \mathrm{qB}$ alleles (eight alleles) and a broader size dispersion for $4 \mathrm{qA}$ alleles compared with $4 \mathrm{qB}$, with a significantly smaller size for D4Z4 arrays on 4qA-type alleles compared with B-type alleles $(\mathrm{p}=0.002$; figure $2 \mathrm{~A})$.

For the $10 \mathrm{q}$ region, the median size of the D4Z4 array is $24 \mathrm{~kb}$ for the 10qA short array ( $\leq 35 \mathrm{~kb} ; 7$ D4Z4 units, $\mathrm{n}=109$ ), $89 \mathrm{~kb}$ for the 10qA long array (>35 kb; 27 D4Z4 units, $n=304)$, and as observed for $4 \mathrm{q}$ alleles, significantly smaller for the $10 \mathrm{qB}$ long array (>35 kb; 24 D4Z4 units, $n=25$; $<<0.001$ ), (figure 2B; online supplementary table 2 ).

By comparing D4Z4 arrays on the $4 \mathrm{qA}$ versus $10 \mathrm{qA}$ chromosomes, we observed a significant difference in size $(\mathrm{p}<0.001)$ (figure 2C). D4Z4 long arrays are usually in a range comprised between 11 and 100 repeats and rarely reaches 150 units as suggested in the literature. Interestingly, the distribution of 10q-type arrays is different. D4Z4 arrays on the 10q chromosome are smaller compared with $4 \mathrm{q}$ with a vast majority of alleles comprised between 11 and 42 units (>35 kb to $140 \mathrm{~kb}$ ).

\section{IDENTIFICATION OF 10QB ALLELES}

Furthermore, we have identified a total of 25 alleles from chromosome $10 \mathrm{q}$ carrying a B-type variant and representing $5.7 \%$ of the 438 chromosomes 10 analysed. In this category, the size of the D4Z4 array ranges between $38 \mathrm{~kb}$ and $166 \mathrm{~kb}$ (11-50 units), in the same size range as the $10 \mathrm{qA}$ alleles. We did not detect any short $10 \mathrm{qB}$ allele.

So far, the proportion of $10 \mathrm{qB}$ alleles has been underestimated since no attempt to determine their frequency in large cohorts has been made. Given the common origin between $4 \mathrm{q}$ and $10 \mathrm{q}$ alleles, $10 \mathrm{qB}$ alleles likely result from the translocation of $4 \mathrm{qB}$ alleles as hypothesised for $4 \mathrm{qA}-10 \mathrm{qA}$ translocations. In a previous study of a large cohort of subjects in the general population, $10 \mathrm{qB}$ frequency was estimated to be $5 \%$, a percentage slightly lower than the percentage that we have estimated by MC (5.7\%). This slight underestimation might be explained by the assumption that $10 \mathrm{q}$ chromosomes were exclusively of type $\mathrm{A}^{2024}$ and by absence of systematic testing of 10qA-type or B-type alleles in SB for FSHD diagnostic purposes. ${ }^{23}$ Indeed, interpretation of HindIII-qA/qB blots is often complex since it is based on the comparative size analysis of four different alleles after hybridisation with the $\mathrm{p} 13 \mathrm{E}-11$ probe and determination of the EcoRI and HindIII fragments, which are not linear. In addition, as detailed below (figure 2D-E), the HindIII-qA-type fragment is highly polymorphic due to the repetitive nature of the $68 \mathrm{bp} \beta$-satellite region while the HindIII-qB fragment devoid of these short tandem repeats is less polymorphic in size.

\section{MC for exploration of the $4 q$ and $10 q$ distal subtelomeric regions}

Despite the global assembly of the human genome, subtelomeric regions remain partially sequenced due to segmental duplications and variability in haplotypes. ${ }^{1-3}$ At $4 \mathrm{q}$ and $10 \mathrm{q}$, the distance between the D4Z4 repeat and the telomere has been estimated between $25 \mathrm{~kb}$ and $40 \mathrm{~kb}$ but the sequences downstream of D4Z4 are poorly described and only partially sequenced. ${ }^{13}$ We took advantage of MC to explore these regions at $4 \mathrm{q}$ and $10 \mathrm{q}$ and determine the size between the end of the D4Z4 array and the telomere (online supplementary tables 3-6). More precisely, we measured the size of the type A allele comprising the $B$ satellite array (figure 2D-E; online supplementary tables 3;4), the size of the B-type allele (online supplementary tables $5 ; 6$ ), the size of the telomeric signal and gaps between the different probes for the $4 \mathrm{q}$ and $10 \mathrm{q}$ regions (online supplementary tables 3-6). Regardless of the number of D4Z4 repeats, the size of the $ß$ satellite-containing region and abutting gap is significantly smaller at the $4 \mathrm{q}$ locus compared with the $10 \mathrm{q}(\mathrm{p}=0.05)$ (figure $2 \mathrm{D})$.

By comparing the 4qA distal region between short and long D4Z4 alleles, we observed significant size differences. The median size for the $ß$ satellite-containing region is larger than the previous estimations of $6.2 \mathrm{~kb}$ with a mean size of $7.5 \mathrm{~kb}$. The size of the subtelomeric sequence between the end of the D4Z4 array and telomere is larger for the short 4qA D4Z4 arrays compared with the long $4 \mathrm{qA}$ arrays $(22.5 \mathrm{~kb}$ vs 17.5 $\mathrm{kb}$, respectively, figure $2 \mathrm{E}$ ) with the distance between the last D4Z4 repeat and the 4qter telomere smaller than the previous 


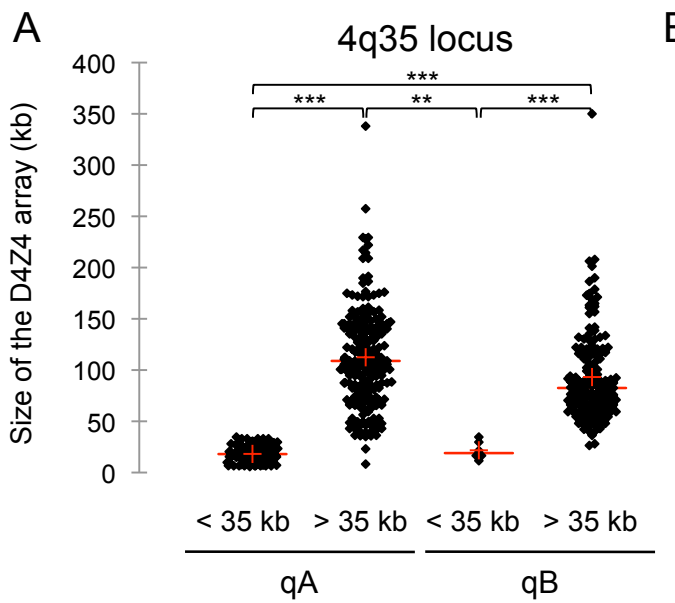

B
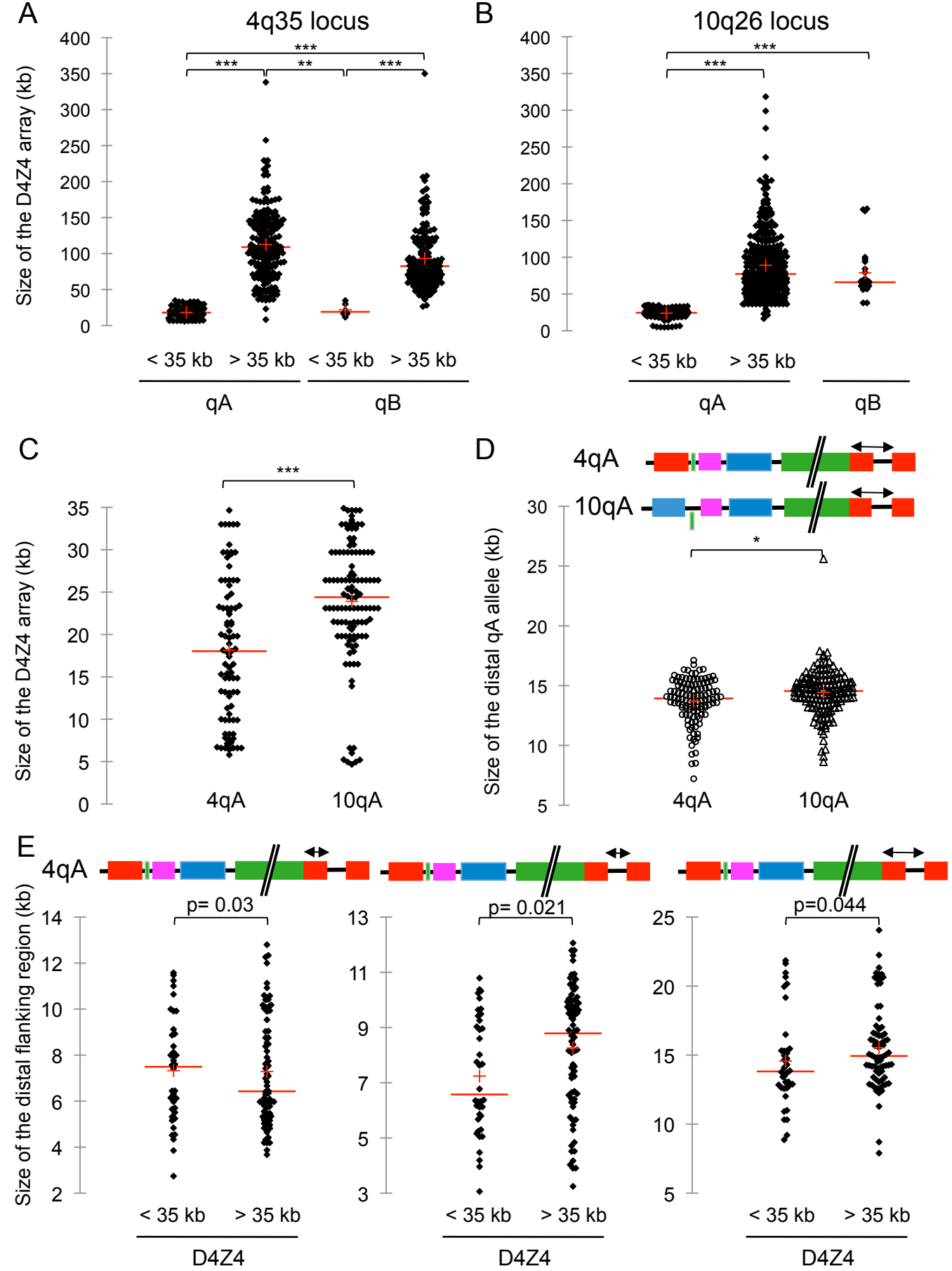

Figure 2 Sequence length variation at the distal $4 q$ and $10 q$ subtelomeres. (A) We determined the distribution of the D4Z4 array size carried by chromosome 4 by analysing signals obtained by molecular combing (MC) in 218 individuals either affected or non-affected with facioscapulohumeral dystrophy (FSHD). In all cases the two $4 \mathrm{q}$ and two $10 \mathrm{q}$ alleles were analysed independently, that is, 436 alleles for each chromosome. Scattergrams display the size distribution. The red line corresponds to the mean size in the different subgroups: short D4Z4 arrays ( $<35 \mathrm{~kb}$ on A-type chromosomes, $\mathrm{n}=86$; mean size $=18.025 \mathrm{~kb}$ ); long D4Z4 arrays ( $>35 \mathrm{~kb}$ on A-type chromosomes, $\mathrm{n}=193$; mean size=108.9 kb); short D4Z4 arrays ( $<35$ kb on B-type chromosomes, $\mathrm{n}=8$; mean size $=23.925 \mathrm{~kb}$ ); long D4Z4 arrays ( $>35 \mathrm{~kb}$ on B-type chromosomes, $\mathrm{n}=149$; mean size=83 kb). (B) Scattergrams of D4Z4 array size carried by chromosome 10 in 218 individuals for short D4Z4 arrays ( $<35$ kb on A-type chromosomes, $n=114$; mean size=24.4 kb); long D4Z4 arrays ( $<35 \mathrm{~kb}$ on A-type chromosomes, $n=299$; mean size $=79.2 \mathrm{~kb}$ ) and B-type chromosomes, $(n=25$; mean size $=66 \mathrm{~kb})$. (C) Size comparison between short $\mathrm{D} 4 \mathrm{Z4}$ arrays $(<35 \mathrm{~kb})$ on 4qA ( $n=86$; mean size $=18.025 \mathrm{~kb}$; five D4Z4 units on average) and 10qA ( $n=114$; mean size=24.4 kb; seven D4Z4 units, on average). (D-E) Schematic representation of the $4 q$ and $10 q$ chromosomes with the region analysed indicated by an arrow. supplementary tables 3-6. The size is indicated in kilobases $(\mathrm{kb})$. The mean size is shown by the red line. Differences in size distribution were determined using a non-parametrical Kruskal-Wallis test with pairwise comparisons and Bonferroni correction for false positives. ${ }^{* *}, p<0.0001 ;{ }^{* *}, p=0.002,{ }^{*}, p=0.003$. (D) We analysed the region distal to D4Z4 containing $\beta$-satellite elements distal to 4qA-type $(n=114)$ or 10qA-type $(n=158)$ chromosomes. (E) Scattergrams of the qA distal region containing $\beta$-satellite element (left graph), distal gap (middle graph) and total qA region on chromosome 4 with short ( $<35 \mathrm{~kb}$ ) or long (>35 kb) D4Z4 arrays. 
estimation of $25-40 \mathrm{~kb}$. The complexity of this subtelomeric region also reveals an increased distance between the last D4Z4 repeat and the telomere in patients with FSHD compared with healthy individuals.

The median size of $B$ satellite-containing sequence is $5.33 \mathrm{~kb}$ and $6.12 \mathrm{~kb}$ respectively for short $10 \mathrm{qA}$ D4Z4 array ( $\leq 35 \mathrm{~kb}$; $\mathrm{n}=38$ ) and long $10 \mathrm{qA}$ array $(>35 \mathrm{~kb} ; \mathrm{n}=119)$ with a significant difference between the two groups (p-values 0.015 ) (online supplementary tables 4;5). The median size of $B$ satellite-containing sequence and the upstream gap is $13.82 \mathrm{~kb}$ for short $10 \mathrm{qA}$ D4Z4 array $(\leq 35 \mathrm{~kb} ; \mathrm{n}=38)$ and $14.63 \mathrm{~kb}$ for $10 \mathrm{qA}$ long array $(>35 \mathrm{~kb} ; \mathrm{n}=123)$ with a significant difference between the two groups $(p=0.019)$. The median length of the $\beta$-satellite sequence, the gap and the telomeric sequence is significantly different between the short 10qA D4Z4 array ( $\leq 35 \mathrm{~kb} ; \mathrm{n}=38$; $23.9 \mathrm{~kb})$ and the long $10 \mathrm{qA}$ array ( $>35 \mathrm{~kb} ; \mathrm{n}=123 ; 25.02 \mathrm{~kb}$, $\mathrm{p}=0.017$ ) (online supplementary table 4 ).

\section{Characterisation of patients with FSHD with complex genotypes}

Between 2012 and 2017, we analysed 1029 individuals by MC, either for FSHD molecular diagnosis, exclusion diagnosis or familial segregation studies. We identified atypical $4 \mathrm{q}$ or $10 \mathrm{q}$ genotypes in $8.7 \%$ of the cases (figure 1). This subcategory includes individuals carrying a cis-duplication of the 4q35 region that we initially described in 15 individuals corresponding to 14 patients affected with FSHD and 1 non-affected carrier. ${ }^{25}$ Nine additional cases have been characterised with the same cis-duplication since our previous publication. ${ }^{25}$ Among the rest of these $8.7 \%$ of cases, somatic mosaicism was detected in $2.8 \%$ of patients presenting with clinical signs of FSHD (online supplementary table 7). For each patient, the percentage of mosaicism was determined by counting the proportion of short versus long D4Z4 arrays. This percentage ranges from 6\% to 52\% of cells carrying a short D4Z4 allele. All patients displayed a significant decrease in D4Z4 methylation (Roche et al, submitted) and none of the 12 patients analysed by whole-exome sequencing were carriers of an SMCHD1 pathogenic mutation suggesting that the short 4qA allele is pathogenic. Of note, two of these patients presented with $4 \mathrm{q}$ mosaicism segregating with a complex $10 \mathrm{qA}$ allele consisting of a cis-duplication of a long D4Z4 array (80 $\mathrm{kb}, 24 \mathrm{D} 4 \mathrm{Z} 4$ units) followed by a sequence corresponding to the A-type probe and a second array of $3 \mathrm{~kb}$ (1 D4Z4 unit) followed by an A-type probe.

\section{CHARACTERISATION OF THE 4Q REGION AND IDENTIFICATION OF PATIENTS WITH DELETION OF THE P13E-11 PROBE REGION}

We have identified four cases of large deletions encompassing part of the D4Z4 array and the proximal region that hybridises the p13E-11 probe (figure 3, online supplementary table 8).

The first index case (patient $100519 \mathrm{~A}$ ) is a patient of Lebanese origin affected with a typical familial form of FSHD. The index case carries a D4Z4 array of $18 \mathrm{~kb}$ (five units) that segregates with deletion of the $\mathrm{p} 13 \mathrm{E}-11$ probe region on the same chromosome. The patient's relatives have been also been explored by MC. The deleted allele is present in three out of six siblings who are also affected with FSHD. The deletion was transmitted from the father also affected by the disease (figure $3 \mathrm{~A}$ ). The second case (1211 108A, online supplementary table 8) carries a proximal deletion of the $\mathrm{p} 13 \mathrm{E}-11$ probe region together with a short three unit D4Z4 array.
In these two cases, the proximal deletion segregates with a short D4Z4 which is likely pathogenic. DNA methylation was tested in these two patients for the DR1 region by sodium bisulfite sequencing and levels were comparable to those observed in patients with FSHD1 (50\% and $44.1 \%$ of methylated CG, respectively).

The third (14 668) and fourth (19 185) patients are affected with FSHD and carry a deletion of the $\mathrm{p} 13 \mathrm{E}-11$ probe region that segregates with a $12 \mathrm{D} 4 \mathrm{Z} 4$ repetitive array (figure $3 \mathrm{~B}$, online supplementary table 8 ) and thus do not correspond to the definition of FSHD1. Patient 14668 displays a decreased methylation (36\% for the DR1 region) while no hypomethylation was found in the other case $(19185 ; 63.9 \%$ of methylated CG). We excluded FSHD2 in these patients by absence of mutation in SMCHD1 assessed by whole-exome sequencing (online supplementary table 8 ) indicating that the deletion of the proximal region is associated with the disease despite the absence of short $4 \mathrm{qA}$ allele.

In patients 100 519A and 19 185, the deletion also encompasses the magenta probe of $10 \mathrm{~kb}$ proximal to the first D4Z4 repeat with the red probe abutting directly the first macrosatellite. In these cases, and based on the size of the probes, the size of the deleted region upstream of the first D4Z4 repeat is estimated as least of $35 \mathrm{~kb}$.

In this subcategory of patients carrying proximal $4 \mathrm{q}$ deletions, we also report a complex case carrying a long (25 units) D4Z4 repeat on the $4 \mathrm{q}$ chromosome and a complex rearrangement of the other $4 \mathrm{q}$ chromosome consisting of a cis-duplication of a B-type allele with a duplication of one D4Z4 unit followed by a B-type sequence in the proximal part of the repeat followed by a 37 units repeat followed by a B-type sequence (figure $3 \mathrm{C}$ ). By the absence of a pathogenic variant in SMCHD1, we excluded FSHD2 in this patient (online supplementary table 9).

Based on SB analysis and the presence of a single allele after hybridisation with the $\mathrm{p} 13 \mathrm{E}-11$ probe, the frequency of non-canonical deletions that extend into the D4F104S1 hybridisation region has been estimated to be 3\% of FSHD cases. ${ }^{30}$ Deletions of up to $78 \mathrm{~kb}$ upstream of D4Z4 have been reported $^{31}$ with phenotypes compatible with the FSHD clinical spectrum. In case of p13E-11 deletions, SB in PFGE is more efficient to visualise the absence of an allele and detection of the other alleles but remains unsatisfactory and a source of underdiagnosis which might require additional SB experiments and the use of other probes like the 9B6A probe that hybridises to D4Z4. ${ }^{32}$

$\mathrm{MC}$ is thus an interesting tool since the four alleles are directly visible and deletion easily identified by absence of the proximal blue probe common to both $10 \mathrm{q}$ and $4 \mathrm{q}$ alleles and the presence upstream of this probe of the $4 \mathrm{q}$-specific (red) or $10 \mathrm{q}$-specific (blue) probes to exclude breakage of the DNA fibre. Thus, the frequency and size of proximal deletions may be better estimated by MC. In our cohort of patients, we have identified four patients with deletion of this proximal region and one patient with a complex rearrangement. Of note, in the five patients reported here, we have not found any mutation in SMCHD1, including in patients carrying a D4Z4 array $>11$ units indicating that deletion of the proximal region associated or not with a short D4Z4 array segregates with typical signs of the disease. The frequent occurrence of $4 \mathrm{q}$ proximal deletions highlights the importance of this region in the regulation of the locus with the possible presence of regulatory elements such as those corresponding to permissive haplotypes ${ }^{24}$ or putative regulatory elements ${ }^{33} 34$ which remain to be fully characterised. 
A

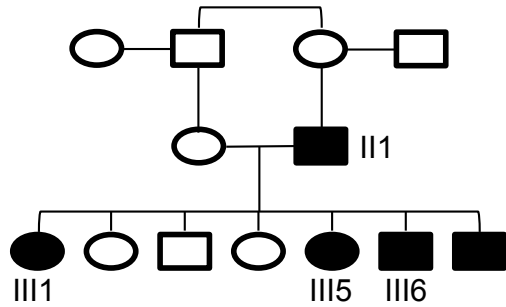

Family 100519A

III1

III5 1116

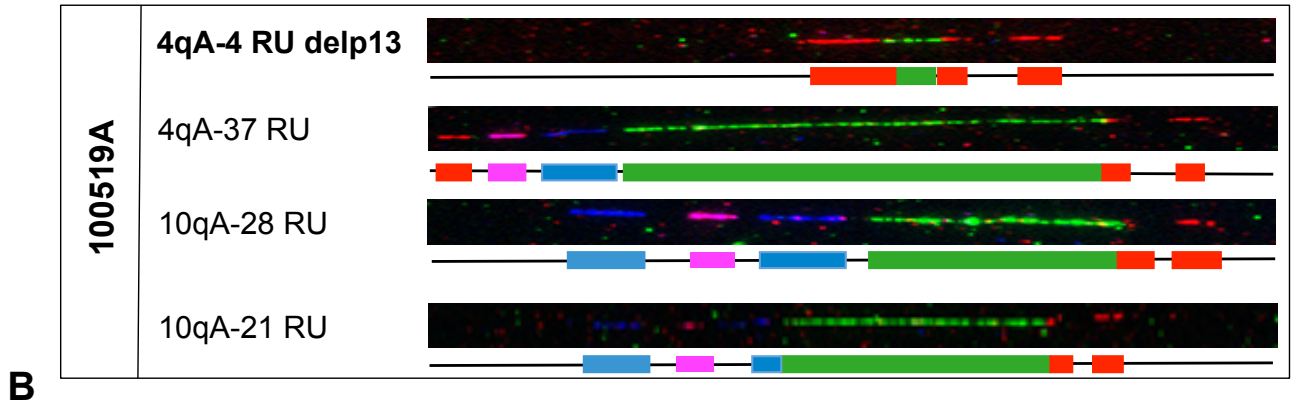

B
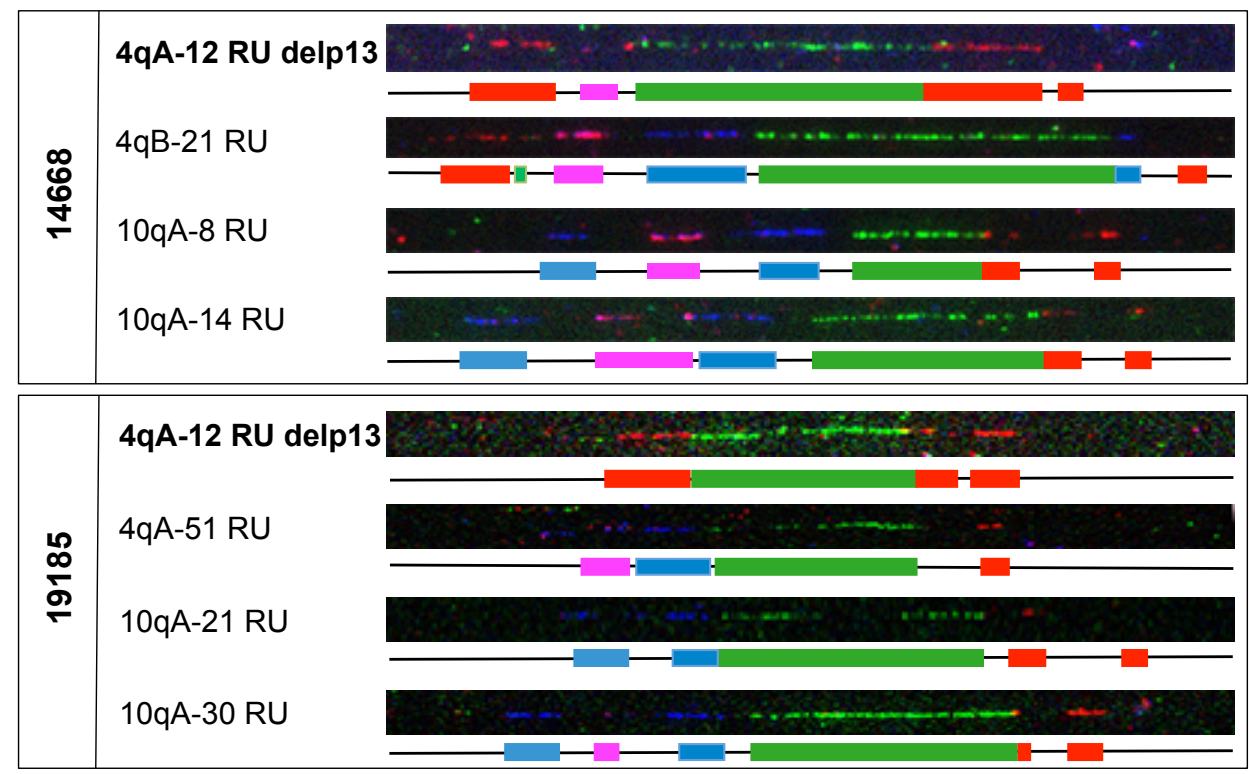

C

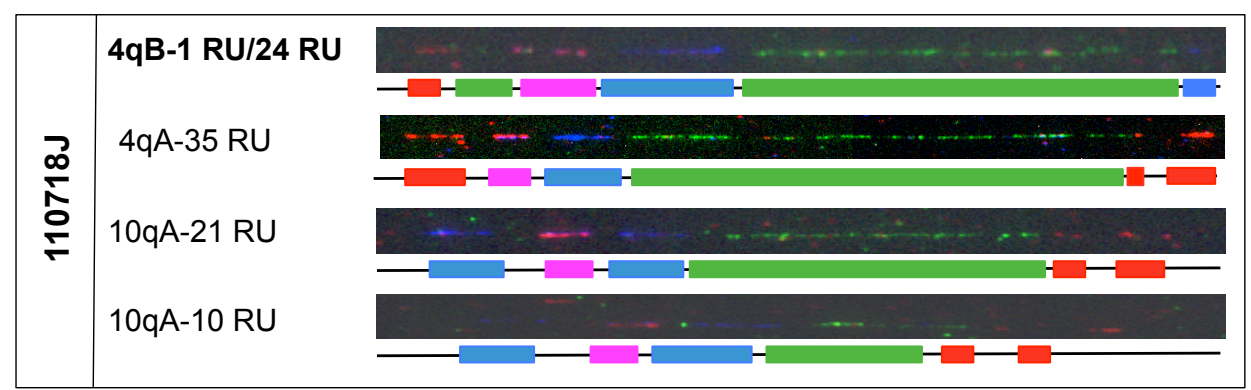

Figure 3 Proximal deletions of the p13E-11 and D4Z4 regions. (A) Pedigree of the family 100 519A with four members in the third generation and one member in the second generation. Representative images of the molecular combing (MC) analysis of patient 00519A-III1 (index case) affected with facioscapulohumeral dystrophy (FSHD). The patient carries a short D4Z4 array and a large deletion of the proximal region encompassing the blue and pink probes. (B) Presentation of other patients identified with a deletion of the p13E-11 probe. The deleted $4 \mathrm{q}$ allele is visualised by the lack of hybridisation of the blue probe corresponding to the p13E-11 region proximal to D4Z4 and the presence of the proximal red probe specific for the $4 \mathrm{q}$ chromosome and the downstream green probe corresponding to D4Z4. In the two patients presented here, the deletion of the proximal region is of different size, with a deletion of the blue probe (patient 14668) or a deletion of the blue and pink probes (patient 19185). Of note, these two patients carry a $>11$ D4Z4 repeats array. In patient 14668, the second $4 q$ allele (4qA) contains 21 repeated units. In patient 19185, the second allele (4qA) contains 51 repeated units. (C) We describe here a complex situation with a patient presenting with an insertion of an $8 \mathrm{~kb}$ D4Z4 repeat (two units) upstream of the pink probe on a type B $4 \mathrm{q}$ allele with 24 repeated units. The second $4 q$ allele contains 35 D4Z4 units. 
A

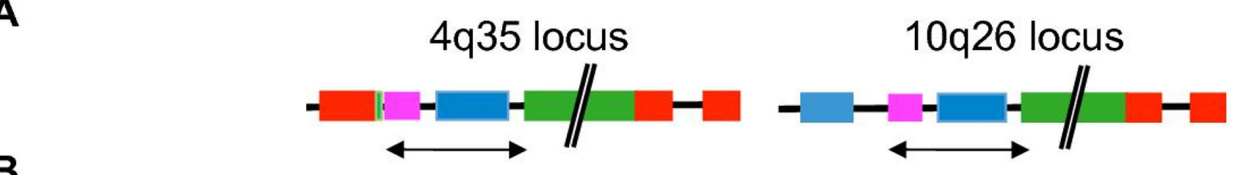

B

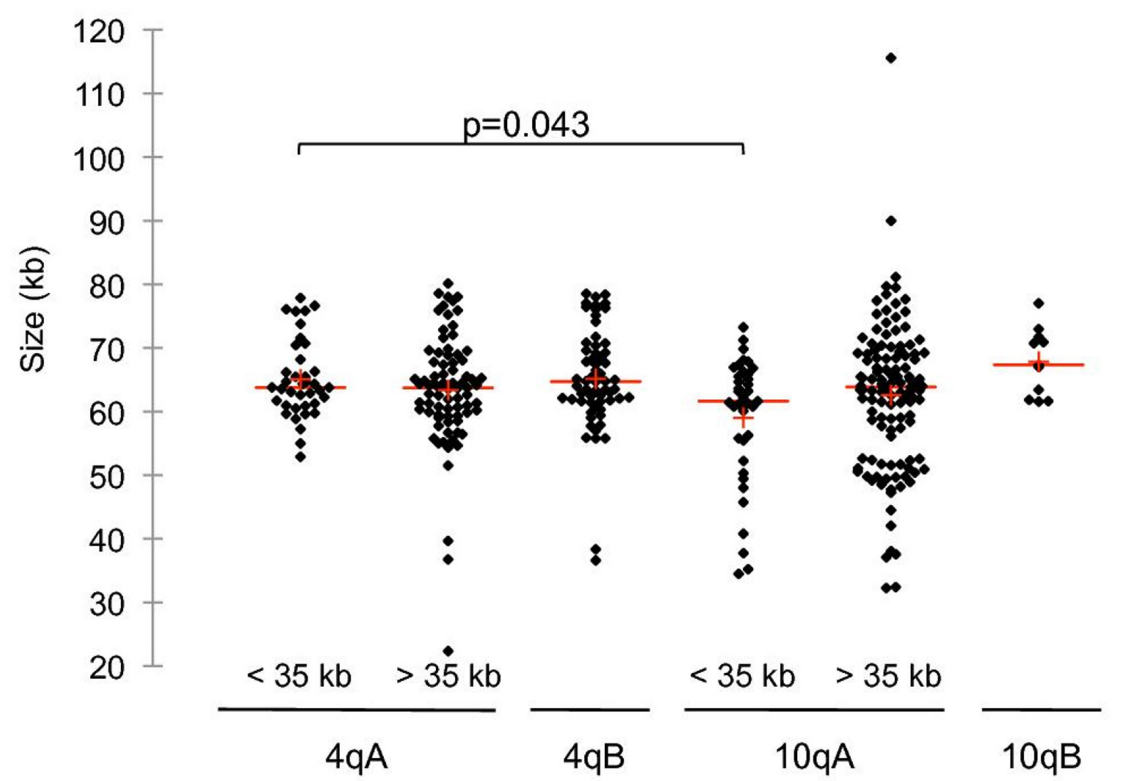

Figure 4 Sequence length variation at the proximal $4 q$ and 10q subtelomeres. (A) Schematic representation of the molecular combing bar code with position of the region. As indicated by an arrow, we analysed the length of the centromeric portion of the 4q35 and 10q36 loci. (B) Scattergrams display the size distribution for the different types of alleles. The red line corresponds to the mean size. The proximal region is identical for the different types of $4 \mathrm{q}$ alleles but more variable between $10 q$ alleles as indicated by the distribution. The proximal region is significantly longer for short $4 q \mathrm{~A}$ alleles compared with short 10qA.

\section{Analysis of the $4 q$ and $10 q$ proximal regions}

Through our analyses of the $4 \mathrm{q}$ and $10 \mathrm{q}$ chromosome ends, we noticed a large variability in the regions hybridised by the proximal probes. We thus analysed the size of the different probes and gaps corresponding to the D4F104S1 (p13E-11) and 4q-specific or $10 \mathrm{q}$-specific regions upstream of the first D4Z4 (online supplementary tables $10 ; 11$, online supplementary figure 3 ). The size of the gap upstream of the first D4Z4 repeat is identical in the different groups of alleles (online supplementary figure $3 \mathrm{~A}$, online supplementary table 11). The p13E-11 probe (blue) with an estimated size of $20 \mathrm{~kb}$ is in the same size range for long, short A-type or B-type $4 \mathrm{q}$ alleles $(11-37.7 \mathrm{~kb})$ but is more variable for the different $10 \mathrm{q}$ chromosomes, ranging between $24.8 \mathrm{~kb}$ to $62.9 \mathrm{~kb}$. An important variability is also observed for the gap located between the blue and magenta probes with an estimated size of $5 \mathrm{~kb}$, at the $4 \mathrm{q}$ end with a size ranging from $3.7 \mathrm{~kb}$ to 26.6 $\mathrm{kb}$, compared with $4.6 \mathrm{~kb}$ to $15 \mathrm{~kb}$ for the $10 \mathrm{q}$ chromosome (online supplementary figure $3 \mathrm{C}$, online supplementary table 11). By individual analysis of the different regions, we did not observe any significant difference in size in the proximal part of the $4 \mathrm{q}$ region between the different types of alleles. However, by combining analyses of the different probes and gaps, between the short 4qA and 10qA alleles, we observed a significant difference in size indicating that despite the estimated $98 \%$ of homology between these subtelomeric regions, the proximal region is also highly variable (figure $4, p=0.043$ ). Altogether these analyses suggest that despite a high conservation between the two chromosome ends, likely due to a 4q-10q duplication during evolution, these subtelomeres are highly prone to recombination and evolved independently.
Frequent detection of triple $10 q$ signals in patients with FSHD Unexpectedly, we have identified additional alleles in a number of patients for the bar code corresponding to the $10 \mathrm{q}$ allele (table 2). These additional chromosome 10 alleles have not been reported previously and might have been unnoticed so far by classical SB analyses. All contained a repetitive D4Z4 array associated with a distal variant qA region. The observed $10 \mathrm{q}$ signals are always independent of the two other $10 \mathrm{q}$ alleles that segregate in a Mendelian way for all samples. In addition, the number of $10 \mathrm{q}$ signals corresponding to this additional allele is high in all cases indicating the absence of artefact and suggesting that these alleles are equally represented.

One hypothesis is that these $10 \mathrm{q}$ alleles correspond to somatic mosaics, as seen for chromosome 4 . Indeed, the frequency of chromosome 4 mitotic rearrangements is high and given the homology between the $10 \mathrm{q}$ and $4 \mathrm{qter}$ regions and occurrence of somatic rearrangement between these two regions, ${ }^{35}$ somatic D4Z4 contraction might likely occur on chromosome 10 as well.

However, in at least three of the families investigated (families 3,4 and 5, table 2), these $10 \mathrm{q}$ alleles are transmitted from the first to the second generation and co-segregate with a normal parental $10 \mathrm{q}$ allele, excluding mosaicism in these cases. In family 4 , the father and the son carry a seven-unit 4qA contracted allele and are affected with FSHD. In addition, the father carries three $10 \mathrm{q}$ alleles of which a 10qA allele has one to two D4Z4 units. This allele was transmitted to his two children independently of the FSHD allele arguing in this family against the implication of this supernumerary allele in FSHD and favouring the hypothesis of the presence of a genomic variant with a $10 \mathrm{q} 26$ duplication, not visible by MC. This additional allele could correspond to 
Table 2 Individuals carrying three copies of the $10 q 26$ locus. We tested the presence of the short or long pLAM sequence associated with a $4 q A$ sequence in most of the cases presented here (underlined). Data are presented in online supplementary figure 5.

\begin{tabular}{|c|c|c|c|c|c|c|}
\hline Patient ID & Gender & $\begin{array}{l}\text { Clinical } \\
\text { status }\end{array}$ & $q A / q B$ & pLAM & $10 q$ & $\begin{array}{l}\text { SMCHD1 } \\
\text { status }\end{array}$ \\
\hline $\begin{array}{l}\text { Family 1-II3 } \\
\text { B2013-1312 }\end{array}$ & $\mathrm{M}$ & Affected & $\begin{array}{l}4 q A 5 R U \\
4 q B 15 R U\end{array}$ & & $\begin{array}{l}\text { 10qA } 11 \mathrm{RU} \\
10 q A 56 \mathrm{RU}\end{array}$ & ND \\
\hline $\begin{array}{l}\text { Family 1-III1 } \\
\text { B2013-1313 }\end{array}$ & $\mathrm{M}$ & Affected & $\begin{array}{l}q A-5 R U \\
q B 26 R U\end{array}$ & $\begin{array}{l}\text { Short } \\
260 \mathrm{bp} \\
4 q \mathrm{~A} \\
\text { fragment }\end{array}$ & $\begin{array}{l}\text { qA } 7 \mathrm{RU} \\
\text { qA } 20 \mathrm{RU} \\
\text { qA } 54 \mathrm{RU}\end{array}$ & ND \\
\hline $\begin{array}{l}\text { Family 2-13 } \\
27176\end{array}$ & $\mathrm{~F}$ & Affected & $\begin{array}{l}4 q A-4 R U \\
4 q A-22 R U \\
\text { Southern blot }\end{array}$ & & & ND \\
\hline $\begin{array}{l}\text { Family 2-II3 } \\
090416 \mathrm{~A} \\
\text { Index case }\end{array}$ & $\mathrm{F}$ & Affected & $\begin{array}{l}q A-4 R U \\
q B-13 R U\end{array}$ & $\begin{array}{l}\text { Short } \\
260 \mathrm{bp} \\
4 q A \\
\text { fragment }\end{array}$ & $\begin{array}{l}q A-2 \mathrm{RU} \\
q A-33 \mathrm{RU} \\
q A-64 \mathrm{RU}\end{array}$ & ND \\
\hline $\begin{array}{l}\text { Family 2-II7 } \\
090415 \mathrm{~A}\end{array}$ & $\mathrm{M}$ & Affected & $\begin{array}{l}4 q A 4 R U \\
4 q A 22 R U\end{array}$ & & $\begin{array}{l}10 q A 30 \mathrm{RU} \\
10 q A 30 \mathrm{RU}\end{array}$ & ND \\
\hline $\begin{array}{l}\text { Family 3-I1 } \\
14728\end{array}$ & $\mathrm{~F}$ & Affected & $4 q A-5 R U$ & $\begin{array}{l}\text { Short } \\
260 \mathrm{bp} \\
4 q A \\
\text { fragment }\end{array}$ & $\begin{array}{l}10 q A-1 \mathrm{RU} \\
10 q 4-20 \mathrm{RU} \\
10 q A-29 \mathrm{RU}\end{array}$ & ND \\
\hline $\begin{array}{l}\text { Family 3-12 } \\
14727 \\
\end{array}$ & $\mathrm{M}$ & Non affected & $4 q B-8 R U$ & $\begin{array}{l}\text { Long } \\
330 \mathrm{bp} \\
4 \mathrm{qA} \\
\text { fragment }\end{array}$ & & ND \\
\hline $\begin{array}{l}\text { Family 3-II1 } \\
\frac{120723 \mathrm{~F}}{\text { Index case }}\end{array}$ & $\mathrm{M}$ & Affected & $\begin{array}{l}4 q A-5 R U \\
4 q B-8 R U\end{array}$ & $\begin{array}{l}\text { Short } \\
260 \mathrm{bp} \\
4 q A \\
\text { fragment }\end{array}$ & $\begin{array}{l}\text { 10qA-2RU } \\
10 q A-7 \text { RU } \\
10 q A-29 \text { RU }\end{array}$ & ND \\
\hline $\begin{array}{l}\text { Family 3-II2 } \\
120628 \mathrm{C} \\
\end{array}$ & $\mathrm{M}$ & Non affected & $\begin{array}{l}4 q A-27 R U \\
4 q A-29 R U\end{array}$ & $\begin{array}{l}\text { Short } \\
260 \text { bp } \\
4 q A \\
\text { fragment }\end{array}$ & $\begin{array}{l}10 q A-2 R U \\
10 q A-14 R U \\
10 q A-29 R U\end{array}$ & ND \\
\hline $\begin{array}{l}\text { Family } 4-12 \\
\frac{100726 C}{\text { Index case }}\end{array}$ & $\mathrm{M}$ & Non affected & $\begin{array}{l}4 q A-7 R U \\
4 q A-27 R U\end{array}$ & $\begin{array}{l}\text { Short } \\
260 \text { bp } \\
4 q A \\
\text { fragment }\end{array}$ & $\begin{array}{l}10 q A-1 \mathrm{RU} \\
10 q A-5 \mathrm{RU} \\
10 q A-18 \mathrm{RU}\end{array}$ & ND \\
\hline $\begin{array}{l}\text { Family 4-I3 } \\
100726 B\end{array}$ & $\mathrm{~F}$ & Non affected & $\begin{array}{l}4 q A-45 R U \\
4 q B-14 R U\end{array}$ & $\begin{array}{l}\text { Short } \\
260 \text { bp } \\
4 q A \\
\text { fragment }\end{array}$ & $\begin{array}{l}10 q A-1 \text { RU } \\
10 q A-5 R U \\
10 q A-28 R U\end{array}$ & ND \\
\hline $100726 \mathrm{~A}$ & $\mathrm{M}$ & & $\begin{array}{l}4 q A-7 R U \\
4 q A-39 R U\end{array}$ & $\begin{array}{l}\text { Short } \\
260 \mathrm{bp} \\
4 q \mathrm{~A} \\
\text { fragment }\end{array}$ & $\begin{array}{l}10 q A-1 \mathrm{RU} \\
10 q A-19 \mathrm{RU} \\
10 q 4-28 \mathrm{RU}\end{array}$ & ND \\
\hline $\begin{array}{l}\text { Family 5-I1 } \\
15571\end{array}$ & $\mathrm{~F}$ & Non affected & $\begin{array}{l}4 q A-20-24 R U \\
4 q B-55 R U\end{array}$ & $\begin{array}{l}\text { Short } \\
260 \text { bp } \\
4 q A \\
\text { fragment }\end{array}$ & $\begin{array}{l}10 q A-1-2 \mathrm{RU} \\
10 q A-39 \mathrm{RU}\end{array}$ & ND \\
\hline $\begin{array}{l}\text { Family 5-12 } \\
15572\end{array}$ & $\mathrm{M}$ & Non affected & $\begin{array}{l}4 q A-45 R U \\
4 q B-38 R U\end{array}$ & $\begin{array}{l}\text { Short } \\
260 \mathrm{bp} \\
4 q A \\
\text { fragment }\end{array}$ & $\begin{array}{l}10 q A-9 \text { RU } \\
10 q A-17 \text { RU }\end{array}$ & ND \\
\hline $\begin{array}{l}\text { Family 5-II1 } \\
15573 \\
\text { Index Case }\end{array}$ & $M$ & Affected & $\begin{array}{l}4 q A-21 R U \\
4 q B-38 R U \\
q A>20 R U\end{array}$ & $\begin{array}{l}\text { Short } \\
260 \mathrm{bp} \\
4 q A \\
\text { fragment }\end{array}$ & $\begin{array}{l}10 q A-1-2 R U \\
10 q A-15 R U \\
10 q A-38 R U\end{array}$ & $\underline{\text { WT }}$ \\
\hline B2014-2538 & $\mathrm{M}$ & Affected & $\begin{array}{l}q A-42 R U \\
q B-23 R U \\
q A>20 R U\end{array}$ & & $\begin{array}{l}q A-1-2 \mathrm{RU} \\
q A-21 \mathrm{RU} \\
q A-33 \mathrm{RU}\end{array}$ & ND \\
\hline B2015-0851 & $\mathrm{M}$ & Affected & $\begin{array}{l}q A-36 \mathrm{RU} \\
q B-23 \mathrm{RU} \\
q A>20 \mathrm{RU}\end{array}$ & $\begin{array}{l}\text { Short } \\
260 \text { bp } \\
4 q A \\
4 q A\end{array}$ & $\begin{array}{l}\text { qA 1-2 RU } \\
q A-8 R U \\
q A-44 R U\end{array}$ & WT \\
\hline
\end{tabular}


Table 2 Continued

\begin{tabular}{|c|c|c|c|c|c|c|}
\hline Patient ID & Gender & $\begin{array}{l}\text { Clinical } \\
\text { status }\end{array}$ & $q A / q B$ & pLAM & $10 q$ & $\begin{array}{l}\text { SMCHD1 } 1 \\
\text { status }\end{array}$ \\
\hline B2013-1393 & $\mathrm{F}$ & Affected & $\begin{array}{l}q A 54 R U \\
q A 54 R U \\
q A \geq 20 R U\end{array}$ & $\begin{array}{l}\text { Short } \\
260 \text { bp + long } 330 \text { bp } \\
4 q A \\
\text { fragments }\end{array}$ & $\begin{array}{l}\text { qA 1-2 RU } \\
\text { qA } 9 \text { RU } \\
\text { qA } 32 \mathrm{RU}\end{array}$ & WT \\
\hline B2016-1344 & $M$ & Affected & $\begin{array}{l}4 q A 57 R U \\
4 q B 22 R U \\
q A>20 R U\end{array}$ & $\begin{array}{l}\text { Short } \\
260 \mathrm{bp} \\
4 q A \\
\text { fragment }\end{array}$ & $\begin{array}{l}10 \mathrm{qA} 1-2 \mathrm{RU} \\
10 \mathrm{qA} 9 \mathrm{RU} \\
10 \mathrm{qA} 63 \mathrm{RU}\end{array}$ & WT \\
\hline B2016-2473 & $M$ & Affected & $\begin{array}{l}\text { 4qA } 25 \mathrm{RU} \\
\text { +Cis duplication } 6520 \mathrm{RU})+9 \mathrm{RU} \\
\mathrm{qA}>20 \mathrm{RU}\end{array}$ & $\begin{array}{l}\text { Short } \\
260 \text { bp +long } 330 b p \\
4 q A \\
4 q A\end{array}$ & $\begin{array}{l}10 \mathrm{qA} 2-3 \mathrm{RU} \\
10 \mathrm{qA} 4-5 \mathrm{RU} \\
10 \mathrm{qA} 30 \mathrm{RU}\end{array}$ & WT \\
\hline B2016-2376 & $M$ & Affected & $\begin{array}{l}4 q A 39 R U \\
4 q A 44 R U \\
q A>20 R U\end{array}$ & $\begin{array}{l}\text { Short } \\
260 \text { bp } \\
4 q A \\
\text { fragment }\end{array}$ & $\begin{array}{l}10 \mathrm{qA} 1-2 \mathrm{RU} \\
10 \mathrm{qA} 6-7 \mathrm{RU} \\
\text { 10qA 9-11 RU }\end{array}$ & WT \\
\hline
\end{tabular}

a complex rearrangement of the 10 qter with a cis-duplication of the region containing D4Z4, the proximal chromosome 10 -specific sequences, and the distal $\mathrm{qA}$ sequence as described for chromosome $4 .^{25}$

In family 3, the supernumerary $10 \mathrm{q}$ allele (10qA at 2 units) segregates with the same maternal $10 \mathrm{q}$ allele (10qA at 29 units) in both sons. In this case again we cannot exclude the presence of a cis-duplication.

In the remaining kindreds, the size of stretched DNA molecules and the absence of detection of large size 10qter signal as described for the 4 qter region ${ }^{25}$ is not in favour of tandem duplications. To retain the explanation of a cis-duplication, it would be necessary to imagine that the two $10 \mathrm{q}$ signals are at a distance of $300 \mathrm{~kb}$ or more and thus always separated by a random break occurring between the two during the stretching process and therefore never visible on the same fibre. This hypothesis is not likely given the number of signals analysed in the different cases presented. Another alternative would be that the additional $10 \mathrm{q}$ allele is located on another chromosome, by duplication of the region and insertion into another region of the genome. We tested this hypothesis by performing FISH, an experiment on metaphase chromosomes, a technique suitable for the analysis of chromosomal rearrangements of large sizes. The D4Z4 probe hybridises to chromosomes 4 and 10 with a variable intensity likely dependent on the size of the D4Z4 array. We did not observe any additional spot on another chromosome excluding the presence of an additional contracted 10q allele. If the two loci were duplicated in tandem and are at least $3 \mathrm{Mb}$ apart, the resolution of FISH would allow seeing two distinct spots on the same chromosome. In this scheme, the two loci would be too distant to be seen together by MC and too close to be distinguished by two spots by FISH. If the two loci were duplicated in tandem and close enough to give only one signal in FISH, the difference in signal intensity between the two alleles would not be visible in FISH but likely visible by MC.

Contractions of D4Z4 on chromosome $10 \mathrm{q}$ are not a priori pathogenic and accordingly, in a number of cases presented here, the additional 10q contracted allele does not always segregate with FSHD, so its involvement in FSHD pathogenesis is questionable. Nevertheless in six cases with clinical FSHD, the additional short $10 \mathrm{qA}$ allele segregates with the disease and two long $4 \mathrm{qA}$ alleles suggesting that it might be causative. None of these six patients carries a mutation in the SMCHD1 gene.
Of note, in this subgroup of affected individuals, several cases carry a short $4 \mathrm{qB}$-type allele together with a long ( $>20$ units) 4qA-type allele (case 15573 [family 5-II1], B2014-2538, B20150851, B2016-1344) (table 2). One of these patients, also carries a cis-duplication of the 4qter region with a stretch of 20 D4Z4 elements followed by a nine repeats array on a type A chromosome. Interestingly, these individuals developed FSHD during childhood suggesting that this short $10 \mathrm{q}$ allele might contribute to the disease or act as a modifier in disease severity.

\section{Detection of the permissive pLAM sequence in patients with atypical genotypes}

In our cohort of atypical cases, we tested the presence of the pLAM sequence associated with stabilisation of the DUX4 transcript produced from the last D4Z4 unit and adjacent A-type sequence. Primers for the short $4 \mathrm{qAS}$ or long $4 \mathrm{qAL}$ sequences, specific to A-type alleles and unable to amplify $4 \mathrm{qB}$ or $10 \mathrm{qA}$ alleles have been previously described. ${ }^{36}$ We were able to amplify the 4qAS fragment in 19 out of the 20 atypical cases tested and detected only the $4 \mathrm{qAL}$ variant in the remaining sample (sample 4 , online supplementary figure 5). For five individuals, both the 4qAS and 4qAL fragments were detected (samples 2, 16, 19, 21, 22). All PCR fragments were sequenced and match the previously reported sequences. ${ }^{36}$

\section{CONCLUDING REMARKS}

Using MC, we explored a large cohort of patients affected with FSHD for whom the genetic cause of the disease had not been resolved and estimated to be approximately $20 \%$ of clinically affected individuals. Among those, we previously reported the existence of cis-duplications of the 4qter region present in $2 \%-2.9 \%$ of the population ${ }^{25} 37$ and in 15 individuals corresponding to 10 FSHD families. The duplication segregates with a short D4Z4 array on the second $4 \mathrm{q}$ allele in $3 / 11$ cases or mutation in SMCHD1 in 5/10 families suggesting that it might be associated with FSHD1 or FSHD2, respectively. Yet, the cis-duplication is the only genetic defect that segregates with clinical signs of the disease in $2 / 10$ of our cases and in a proportion of cases later reported by Lemmers et $a l^{37}$ suggesting that it might also be causal in a small number of patients. ${ }^{25}$ Since our initial publication describing this recurrent $4 \mathrm{q} 35$ rearrangement, we have identified nine additional patients displaying the same 
cis-duplication of the $4 \mathrm{q} 35$ region, accounting for $5.16 \%$ of all clinically affected cases reported in this study.

In addition, we report here the presence in patients clinically affected with FSHD of typical $4 \mathrm{q}$ alleles with deletion of the region proximal to the first D4Z4 repeat (D4F104S1), including in patients carrying a normal D4Z4 array size (three out of six). We also report the presence of an additional $10 \mathrm{q}$ allele in 11 unrelated families. Based on our MC data, cis-duplications are less frequent on chromosome 10 than on chromosome 4 and never observed in the control population while additional $10 \mathrm{q}$ alleles were detected in patients with clinical signs of the disease. As observed for $4 \mathrm{q} 35$ cis-duplications, the absence of uniformity within each class of genomic variants argues against the existence of founder alleles and underlines the propensity of recombination of these two subtelomeric regions. In this group, none of the patients tested is mutated for SMCHD1 or displayed a marked hypomethylation suggestive of a mutation in the DNMT3B gene. Strikingly, the vast majority of them (7 out of 11$)$ carries a very short (1-3 units) $10 \mathrm{q}$ allele and a $4 \mathrm{q}$ chromosome with more than 20 units escaping the recent definition of FSHD2 proposed as a subclass of patients carrying between 8-20 repeated units, with cis-duplication carriers included in this subgroup based on the size of the most proximal D4Z4 array and regardless of the size of the proximal one. ${ }^{37}$ Thus, if the definition of FSHD2 as individuals carrying 8-20 repeats can be applied to many patients, recent examples including those previously described ${ }^{25}$ or those reported here (figure 1) indicate that a significant number of patients clinically diagnosed with FSHD cannot be classified in this way or might be discarded if this restrictive classification is applied. Interestingly, in our cohort of patients comprising 426 cases clinically diagnosed with FSHD, the percentage of patients carrying a mutation in SMCHD1 is close to the percentage of patients in whom we found an additional $10 \mathrm{q}$ allele and lower than the total percentage of patients with atypical genomic features (table 1). Furthermore, all atypical cases carry $4 \mathrm{qAS}$ or $4 \mathrm{qAL}$ alleles, with a higher proportion of $4 \mathrm{qAS}$ alleles, including in patients carrying very large D4Z4 arrays (B2016-2473, B2015-0851, B2013-1393, table 2) and severely affected.

Given the heterogeneity of subtelomeric regions between individuals, assembly remains incomplete, limiting comprehensive analyses. This observation is perfectly illustrated by our analyses of a large number of $4 \mathrm{q}$ and $10 \mathrm{q}$ alleles by MC revealing the large size variability among alleles, including in the proximal region corresponding to the different SSLPs and deleted in a few patients. Interestingly since differences in telomere lengths of different haplotypes have been observed, ${ }^{38-40}$ this opens a broad field for further investigations for telomere biology and diseases linked to subtelomeric imbalance. Visualisation by MC can thus be considered as a valuable tool for improving the quality of genome assembly in complex regions together with other sequencing methodologies. ${ }^{14142}$ Overall, the in-depth analysis of 4 qter and 10 qter regions in a very large group of samples emphasises the complexity of these subtelomeric loci.

More importantly, our work also highlights the wide heterogeneity in the molecular signature of FSHD and the difficulty of interpretation of the molecular data in a significant proportion of cases, especially for genetic counselling or prenatal testing. ${ }^{25} 2643$

\section{Author affiliations}

${ }^{1}$ Medical Genetics, Assistance Publique Hopitaux de Marseille, Marseille, France
${ }^{2}$ Aix Marseille Univ, INSERM, MMG, Marseille Medical Genetics U1251, Marseille, France

${ }^{3}$ Genetique, Institut Jerome Lejeune, Paris, France

${ }^{4}$ Pôle Soins de suite et réadaptation handicaps lourds et maladies rares neurologiques, Hôpital Marin, Assistance publique des hopitaux de Paris, Hendaye, France

${ }^{5}$ Hopital Pierre Zobda-Quitman, Fort-de-France, France

${ }^{6}$ Service de Neurologie infantile, Université Paris Descartes, Sorbonne Paris Cité, Hôpital Necker-Enfants Malades, Assistance Publique-Hôpitaux de Paris, Paris, France ${ }^{7}$ Centre de Référence de Maladies Neuromusculaires Garches-Necker-MondorHendaye (GNMH), Réseau National Français de la Filière Neuromusculaire (FILNEMUS), Paris, France

${ }^{8}$ Génétique Médicale, CHU-Nantes, Nantes, France

${ }^{9}$ Assistance Publique - Hopitaux de Paris, Paris, , France

${ }^{10}$ Service de Génétique Médicale, Centre De Référence Anomalies du

Développement, CHU de Rennes, Rennes, France

${ }^{11}$ Centre référent maladies neuromusculaires rares, Hospices Civils de Lyon, Hôpital

Femme Mère Enfant, Bron, France

${ }^{12}$ Peripheral Nervous System, Muscle and ALS Department, Université Côte d'Azur, Nice, France

${ }^{13}$ Institute for Research on Cancer and Aging of Nice, Université Côte d'Azur, Faculty of Medicine, Nice, France

${ }^{14}$ Centre de Référence des Maladies Neuromusculaires, service de Médecine Physique et de Réadaptation, Centre hospitalier régionale de Lille, Lille, France

${ }^{15}$ Centre de Référence des Maladies Neuromusculaires, CHU Morvan, Brest, France

${ }^{16}$ Service de Neuropédiatrie, CHRU de Lille, Lille, France

${ }^{17}$ Centre de reference des maladies neuromusculaires, Assistance Publique Hopitaux de Marseille, Marseille, France

Acknowledgements The authors thank all families and patients for participating in this study.

Contributors $\mathrm{KN}$ designed the study, supervised, conducted, analysed the combing experiments, and conducted a survey of the data presented. NB analysed the molecular combing data. SR performed and analysed whole-exome sequencing. JDR performed and analysed the PLAM assays. CV, CC and LG conducted and analysed Southern blots and molecular combing. AM, JAU, RB, CB, AD, BE, MF, VM, SS, VT, $F Z, J M C, E S C$ and SA provided and clinically evaluated patients. RB analysed the MC data, conducted a survey and edited the manuscript. NL designed the study and edited the manuscript. FM analysed the data, wrote, edited and submitted the manuscript. KN and FM are responsible for the overall content as guarantor of the data presented.

Funding This study was funded by Association Française contre les Myopathies (AFM grantsNMDecrypt and TRIM-RD program) and Agence Nationale de la Recherche (ANR,FSHDecipher, ANR-13-BSV1-0001).

Competing interests A patent application (No. EP08165310.7) on molecular combing for the diagnosis of FSHD1 and exploration of D4Z4 has been registered by Genomic Vision, University of the Mediterranean, and Public Assistance of the Hospitals of Marseille. NL is a co-inventor of the patent.

Patient consent for publication Not required.

Provenance and peer review Not commissioned; externally peer reviewed.

\section{REFERENCES}

1 Young E, Pastor S, Rajagopalan R, McCaffrey J, Sibert J, Mak ACY, Kwok P-Y, Riethman H, Xiao M. High-throughput single-molecule mapping links subtelomeric variants and long-range haplotypes with specific telomeres. Nucleic Acids Res 2017;45:e73.

2 Ambrosini A, Paul S, Hu S, Riethman H. Human subtelomeric duplicon structure and organization. Genome Biol 2007;8:R151.

3 Riethman H. Human subtelomeric copy number variations. Cytogenet Genome Res 2008;123:244-52.

4 Arnoult N, Schluth-Bolard C, Letessier A, Drascovic I, Bouarich-Bourimi R, Campisi J, Kim S-ho, Boussouar A, Ottaviani A, Magdinier F, Gilson E, Londoño-Vallejo A. Replication timing of human telomeres is chromosome Arm-Specific, influenced by subtelomeric structures and connected to nuclear localization. PLOS Genet 2010;6:e1000920.

5 Azzalin CM, Reichenbach P, Khoriauli L, Giulotto E, Lingner J. Telomeric repeat containing RNA and RNA surveillance factors at mammalian chromosome ends. Science 2007:318:798-801.

6 Baur JA, Zou Y, Shay JW, Wright WE. Telomere position effect in human cells. Science 2001:292:2075-7.

7 Koering CE, Pollice A, Zibella MP, Bauwens S, Puisieux A, Brunori M, Brun C, Martins L, Sabatier L, Pulitzer JF, Gilson E. Human telomeric position effect is determined by chromosomal context and telomeric chromatin integrity. EMBO reports 2002;3:1055-61. 
8 Stadler G, Rahimov F, King OD, Chen JCJ, Robin JD, Wagner KR, Shay JW, Emerson CP, Wright WE. Telomere position effect regulates DUX4 in human facioscapulohumeral muscular dystrophy. Nat Struct Mol Biol 2013;20:671-8.

9 Lou Z, Wei J, Riethman H, Baur JA, Voglauer R, Shay JW, Wright WE. Telomere length regulates ISG15 expression in human cells. Aging 2009;1:608-21.

10 Kim W, Ludlow AT, Min J, Robin JD, Stadler G, Mender I, Lai T-P, Zhang N, Wright WE, Shay JW. Regulation of the human telomerase gene TERT by telomere position Effect-Over long distances (TPE-OLD): implications for aging and cancer. PLOS Biol 2016;14:e2000016.

11 Robin JD, Ludlow AT, Batten K, Magdinier F, Stadler G, Wagner KR, Shay JW, Wright WE. Telomere position effect: regulation of gene expression with progressive telomere shortening over long distances. Genes Dev. 2014;28:2464-76.

12 Ottaviani A, Gilson E, Magdinier F. Telomeric position effect: from the yeast paradigm to human pathologies?. Biochimie 2008;90:93-107.

13 Laberthonnière C, Magdinier F, Robin JD. Bring it to an end: does telomeres size matter?. Cells 2019;8. doi:10.3390/cells8010030. [Epub ahead of print 08 Jan 2019].

14 Wijmenga C, Brouwer OF, Moerer P, Padberg GW, Wijmenga C, Frants RR, Moerer P, Weber JL. Location of facioscapulohumeral muscular dystrophy gene on chromosome 4. The Lancet 1990;336:651-3.

15 Upadhyaya M, Lunt P, Sarfarazi M, Broadhead W, Farnham J, Harper PS. The mapping of chromosome $4 \mathrm{q}$ markers in relation to facioscapulohumeral muscular dystrophy (FSHD). Am J Hum Genet 1992;51:404-10.

16 Kilmer DD, Abresch RT, McCrory MA, Carter GT, Fowler WM, Jr, Johnson ER. McDonald $\mathrm{cm}$ (1995) profiles of neuromuscular diseases. facioscapulohumeral muscular dystrophy. Am J Phys Med Rehabil 74;(5 Suppl).

17 Wijmenga C, Hewitt JE, Sandkuijl LA, Clark LN, Wright TJ, Dauwerse HG, Gruter A-M, Hofker MH, Moerer P, Williamson R, van Ommen G-JB, Padberg GW, Frants RR. Chromosome $4 q$ DNA rearrangements associated with facioscapulohumeral muscular dystrophy. Nat Genet 1992;2:26-30.

18 Sarfarazi M, Wijmenga C, Upadhyaya M, Weiffenbach B, Hyser C, Mathews K, Murray J, Gilbert J, Pericak-Vance M, Lunt P. Regional mapping of facioscapulohumeral muscular dystrophy gene on 4q35: combined analysis of an international Consortium. Am J Hum Genet 1992;51:396-403.

19 Deutekom JCTV, Wljmenga C, Tlenhoven EAEV, Gruter A-M, Hewitt JE, Padberg GW Ommen G-JBvan, Hofker MH, Fronts RR. FSHD associated DNA rearrangements are due to deletions of integral copies of a $3.2 \mathrm{~kb}$ tandemly repeated unit. Hum $\mathrm{Mol}$ Genet 1993:2:2037-42.

20 Lemmers RJLF, de Kievit P, Sandkuijl L, Padberg GW, van Ommen G-JB, Frants RR, van der Maarel SM. Facioscapulohumeral muscular dystrophy is uniquely associated with one of the two variants of the $4 q$ subtelomere. Nat Genet 2002;32:235-6.

21 van Geel M, Dickson MC, Beck AF, Bolland DJ, Frants RR, van der Maarel SM, de Jong PJ, Hewitt JE. Genomic analysis of human chromosome $10 q$ and $4 q$ telomeres suggests a common origin. Genomics 2002;79:210-7.

22 Lemmers RJLF, van der Vliet PJ, Klooster R, Sacconi S, Camano P, Dauwerse JG, Snider L, Straasheijm KR, Jan van Ommen G, Padberg GW, Miller DG, Tapscott SJ, Tawil R, Frants RR, van der Maarel SM. A unifying genetic model for facioscapulohumeral muscular dystrophy. Science 2010;329:1650-3.

23 Lemmers RJLF, van der Vliet PJ, van der Gaag KJ, Zuniga S, Frants RR, de Knijff P, van der Maarel SM. Worldwide population analysis of the $4 q$ and $10 q$ subtelomeres identifies only four discrete interchromosomal sequence transfers in human evolution. The American Journal of Human Genetics 2010;86:364-77.

24 Lemmers RJLF, Wohlgemuth M, van der Gaag KJ, van der Vliet PJ, van Teijlingen CMM de Knijff P, Padberg GW, Frants RR, van der Maarel SM. Specific sequence variations within the $4 q 35$ region are associated with facioscapulohumeral muscular dystrophy. The American Journal of Human Genetics 2007:81:884-94.

25 Nguyen K, Puppo F, Roche S, Gaillard M-C, Chaix C, Lagarde A, Pierret M, Vovan C, Olschwang S, Salort-Campana E, Attarian S, Bartoli M, Bernard R, Magdinier F, Levy
N. Molecular combing reveals complex 4q35 rearrangements in facioscapulohumeral dystrophy. Human Mutation 2017;38:1432-41.

26 Vasale J, Boyar F, Jocson M, Sulcova V, Chan P, Liaquat K, Hoffman C, Meservey M, Chang I, Tsao D, Hensley K, Liu Y, Owen R, Braastad C, Sun W, Walrafen P, Komatsu J, Wang J-C, Bensimon A, Anguiano A, Jaremko M, Wang Z, Batish S, Strom C, Higgins J. Molecular combing compared to Southern blot for measuring D4Z4 contractions in FSHD. Neuromuscular Disorders 2015;25:945-51.

27 Nguyen K, Walrafen P, Bernard R, Attarian S, Chaix C, Vovan C, Renard E, Dufrane $\mathrm{N}$, Pouget J, Vannier A, Bensimon A, Lévy N. Molecular combing reveals allelic combinations in facioscapulohumeral dystrophy. Ann Neurol. 2011;70:627-33.

28 Bensimon A, Simon A, Chiffaudel A, Croquette V, Heslot F, Bensimon D. Alignment and sensitive detection of DNA by a moving interface. Science 1994;265:2096-8.

29 Lebofsky R, Bensimon A. Single DNA molecule analysis: applications of molecular combing. Briefings in Functional Genomics and Proteomics 2003;1:385-96.

30 Lemmers RJLF, Osborn M, Haaf T, Rogers M, Frants RR, Padberg GW, Cooper DN, van der Maarel SM, Upadhyaya M. D4F104S1 deletion in facioscapulohumeral muscular dystrophy: phenotype, size, and detection. Neurology 2003;61:178-83.

31 Deak KL, Lemmers RJLF, Stajich JM, Klooster R, Tawil R, Frants RR, Speer MC, van der Maarel SM, Gilbert JR. Genotype-phenotype study in an FSHD family with a proximal deletion encompassing p13E-11 and D4Z4. Neurology 2007;68:578-82.

32 Ehrlich M, Jackson K, Tsumagari K, Camaño P, Lemmers RJFL. Hybridization analysis of D4Z4 repeat arrays linked to FSHD. Chromosoma 2007;116:107-16.

33 Cabianca DS, Casa V, Bodega B, Xynos A, Ginelli E, Tanaka Y, Gabellini D. A long ncRNA links copy number variation to a polycomb/trithorax epigenetic switch in FSHD muscular dystrophy. Cell 2012;149:819-31.

34 Himeda CL, Debarnot C, Homma S, Beermann ML, Miller JB, Jones PL, Jones TI. Myogenic enhancers regulate expression of the facioscapulohumeral muscular dystrophy-associated DUX4 gene. Molecular and Cellular Biology 2014;34:1942-55.

35 Lemmers RJLF, van der Wielen MJR, Bakker E, Padberg GW, Frants RR, van der Maarel SM. Somatic mosaicism in FSHD often goes undetected. Ann Neurol 2004;55:845-50.

36 Lemmers RJLF, van der Vliet PJ, Balog J, Goeman JJ, Arindrarto W, Krom YD, Straasheijm KR, Debipersad RD, Özel G, Sowden J, Snider L, Mul K, Sacconi S, van Engelen B, Tapscott SJ, Tawil R, van der Maarel SM. Deep characterization of a common D4Z4 variant identifies biallelic DUX4 expression as a modifier for disease penetrance in FSHD2. Eur J Hum Genet 2018:26:94-106.

37 Lemmers RJLF, van der Vliet PJ, Vreijling JP, Henderson D, van der Stoep N, Voermans $\mathrm{N}$, van Engelen B, Baas F, Sacconi S, Tawil R, van der Maarel SM. Cis D4Z4 repeat duplications associated with facioscapulohumeral muscular dystrophy type 2. Hum Mol Genet 2018;27:3488-97.

38 Baird DM. Telomere dynamics in human cells. Biochimie 2008;90:116-21.

39 Baird DM, Rowson J, Wynford-Thomas D, Kipling D. Extensive allelic variation and ultrashort telomeres in senescent human cells. Nat Genet 2003:33:203-7.

40 McCaffrey J, Young E, Lassahn K, Sibert J, Pastor S, Riethman H, Xiao M. High-throughput single-molecule telomere characterization. Genome Res. 2017;27:1904-15.

41 McCaffrey J, Sibert J, Zhang B, Zhang Y, Hu W, Riethman H, Xiao M. CRISPR-Cas9 D10A nickase target-specific fluorescent labeling of double strand DNA for whole genome mapping and structural variation analysis. Nucleic Acids Res 2016:44:e11.

42 Mitsuhashi S, Nakagawa S, Takahashi Ueda M, Imanishi T, Frith MC, Mitsuhashi H. Nanopore-based single molecule sequencing of the D4Z4 array responsible for facioscapulohumeral muscular dystrophy. Sci Rep 2017;7.

43 Scionti I, Greco F, Ricci G, Govi M, Arashiro P, Vercelli L, Berardinelli A, Angelini C, Antonini G, Cao M, Di Muzio A, Moggio M, Morandi L, Ricci E, Rodolico C, Ruggiero L, Santoro L, Siciliano G, Tomelleri G, Trevisan CP, Galluzzi G, Wright W, Zatz M, Tupler R. Large-scale population analysis challenges the current criteria for the molecular diagnosis of fascioscapulohumeral muscular dystrophy. The American Journal of Human Genetics 2012:90:628-35. 